\title{
$\therefore \div$
}

$|N-7|$

NASA Technical Memorandum 105365

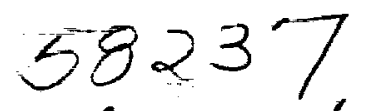

AIAA-92-0501

\section{A Survey of the Broadband Shock Associated Noise Prediction Methods}

Chan M. Kim and Eugene A. Krejsà

National Aeronautics and Space Administration

Lewis Research Center

Cleveland, Ohio

and

Abbas Khavaran

Sverdrup Technology, Inc.

Lewis Research Center Group

Brook Park, Ohio

Prepared for the

30th Aerospace Sciences Meeting and Exhibit

sponsored by the American Institute of Aeronautics and Astronautics

Reno, Nevada, January 6-9, 1992

\section{N/SN}

(NASA-TM-105365) A SURVEY OF THE ERDADBAND

N92-14797 SHCCK ASSOCIATEO NOISE PREDICTION METHODS (NASA) $26 \mathrm{P}$ 


\title{
A SURVEY OF THE BROADBAND SHOCK ASSOCIATED NOISE
}

\section{PREDICTION METHODS}

\author{
Chan M. Kim and Eugene A. Krejsa ${ }^{*}$ \\ National Aeronautics and Space Administration \\ Lewis Research Center \\ Cleveland, Ohio 44135 \\ and \\ Abbas Khavaran \\ Sverdrup Technology, Inc. \\ Lewis Research Center Group \\ Brook Park, Ohio 44142
}

赵

\begin{abstract}
$\underline{\text { Abstract }}$
Several different prediction methods to estimate the broadband shock associated noise of a supersonic jet are introduced and compared with experimental data at various test conditions. The nozzle geometries considered for comparison include a convergent and a convergentdivergent nozzle, both axisymmetric. Capabilities and limitations of prediction methods in incorporating the two nozzle geometries, flight effect, and temperature effect are discussed. Predicted noise field shows the best agreement for a convergent nozzle geometry under static conditions. Predicted results for nozzles in flight show larger discrepancies from data and more dependable flight data are required for further comparison. Qualitative effects of jet temperature, as observed in experiment, are reproduced in predicted results.
\end{abstract}

\section{Nomenclature}

$\mathbf{A}_{\mathrm{j}} \quad$ fully expanded jet area

$\mathrm{a}_{\mathrm{T}} \quad$ speed of sound in open wind tunnel

$a_{\infty} \quad$ ambient speed of sound

D nozzle exit diameter

DPR nozzle design pressure ratio

$\mathrm{D}_{\text {eq }} \quad$ equivalent diameter

$\mathrm{D}_{\mathrm{h}} \quad$ hydraulic diameter

$\mathrm{D}_{\mathrm{j}} \quad$ fully expanded jet diameter

f frequency, $\mathrm{Hz}$

$f_{c} \quad 1 / 3$ octave band center frequency

$f_{m} \quad$ peak frequency of $m^{\text {th }}$ waveguide mode of shock cell structure

$f_{p} \quad$ shock noise peak frequency

${ }^{*}$ Member, AIAA. 


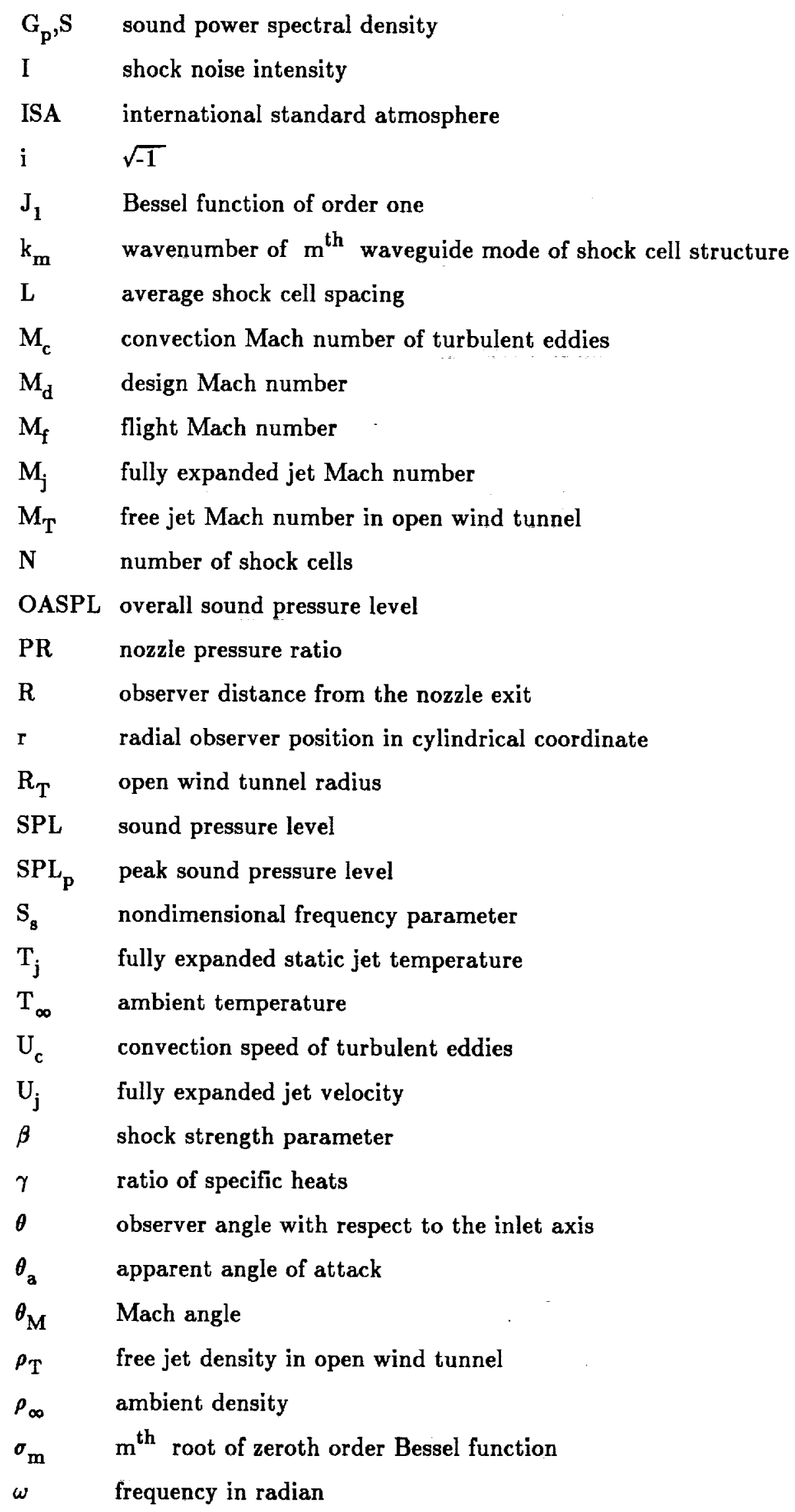




\section{$\underline{\text { Introduction }}$}

One of the technical challenges for the future HSCT (High Speed Civil Transport) is reducing the jet noise to meet the current federal noise regulation (FAR 36, Stage 3). To meet these stricter noise rules the acoustic performance has to be included at the preliminary design stage. It is very critical, therefore, that the key parameters governing the noise generation mechanism be identified and that a reliable noise prediction methodology be developed.

Among three components of a supersonic jet noise (i.e., turbulence mixing noise, broadband shock associated noise and screech tones) the broadband shock associated noise is considered to be the dominant noise component in a certain directional and spectral range at a typical takeoff condition and can be a significant contributor to the overall noise level. Experimental observations indicate that the amplitude of this shock noise is largely determined by the dynamic conditions at the nozzle exit and also that the generation mechanism is distinct from that of the turbulence mixing noise. It may not be unrealistic, therefore, to separately deal with each component of supersonic jet noise for the purpose of understanding the noise generation process and thus predicting and reducing the total radiated noise. The paper presented herein surveys current shock noise prediction methods which provide a direct assessment of the broadband shock associated noise field. After a brief description of these prediction methods both qualitative and quantitative shock noise characteristics predicted by the methods are compared with available experimental results. The prediction capabilities of each method in terms of incorporating the effect of temperature, flight effect and different nozzle geometries are also investigated. It should be noted that the noise prediction formulas introduced here only compute the shock noise field while reported experimental results present the total noise field. Thus the comparison is made in ranges where the shock noise is known to be dominant over the turbulence mixing noise. The emphasis of the work presented herein is to compare and evaluate the existing shock noise prediction methods and thus to suggest future desirable directions. An extensive review on the subject may be found in a paper by Tam. ${ }^{1}$

\section{Shock Noise Generation Mechanism, Characteristics and Models}

The mechanism of the generation of the broadband shock noise is generally believed to be due to the interaction between the fluctuating turbulence structures embedded in the convecting jet plume and the quasi-periodic shock cell structure. When a supersonic jet is imperfectly expanded the pressure mismatch at the nozzle exit is adjusted by means of compression and expansion waves. Successive reflections of these waves at the jet boundary as they propagate downstream produce a quasi-periodic shock cell system which interacts with the convecting turbulence structures to emit wavelike disturbances radiating to the far field. The magnitude and the spectral content of the noise field depend on interference patterns among the emitted disturbances.

The distinctive features of the broadband shock associated noise for choked jets were identified by Harper-Bourne and Fisher's experiment ${ }^{2}$ and further confirmed by Tanna ${ }^{3}$ for wider range of operating conditions. According to their results the intensity of the shock associated noise appears to be principally a function of the jet pressure ratio, and the dependence on either the emission angle or the jet temperature is minimal. This shock associated noise is dominant over the turbulence mixing noise in the forward quadrant region and characterized by a relatively broadband nature with a well-defined peak. The frequency of this peak varies with the observer angle in the manner of a Doppler shift and is also governed by the turbulence convection speed and the shock cell spacing. Tam and Tanna ${ }^{4}$ observed similar characteristics for 
convergent-divergent nozzle geometry and showed the shock noise reduction potential of the convergent-divergent nozzle over a wide envelope of off-design operating conditions.

Based on observed features of the shock noise, Harper-Bourne and Fisher ${ }^{2}$ characterized the dependence of the shock noise intensity on the jet pressure ratio by a shock strength parameter $\beta$ such that

$$
\mathrm{I} \alpha \beta^{4}
$$

where $\beta=\left(M_{j}^{2}-1\right)^{1 / 2}$ and $M_{j}$ is the fully expanded jet Mach number. The agreement of this formula with experimental results is excellent for $\beta<1$ but beyond this range it overestimates the noise intensity. With regard to this limitation of the formula Seiner and Norum ${ }^{5}$ observed that a Mach disk begins to form for larger shock strength parameter and both the downstream shock cell strength and shock cell noise eventually diminish with the appearance of strong imbedded shocks. The value of the shock strength parameter at which this nonlinear variation of the shock noise intensity begins depends on the nozzle operating conditions. By extending Powell's model $^{6}$ for the analysis of screech tones Harper-Bourne and Fisher ${ }^{2}$ proposed a point source array model where the acoustic energy source is located at the end of each shock cell and the relative phasing between the sources is correlated by the spacing and the convection speed of turbulent eddies between them. This model results in a peak frequency formula for the broadband shock noise given by

$$
f_{p}=U_{c} /\left[L\left(1+M_{c} \cos \theta\right)\right]
$$

where $U_{c}$ is the convection speed of turbulent eddies, $L$ is the average shock cell spacing, $\theta$ is the observer angle with respect to the inlet axis, and $M_{c}=U_{c} / a_{\infty}$ with $a_{\infty}$ denoting the ambient speed of sound. Similar formulas for the noise intensity and the peak frequency were later derived by Tam and Tanna ${ }^{4}$ for the convergent-divergent nozzle geometries and are given by

$$
\begin{gathered}
I \alpha\left(M_{j}^{2}-M_{d}^{2}\right)^{2} \\
f_{p}=U_{c} /\left[L\left(1+M_{c} \cos \theta\right)\right]
\end{gathered}
$$

where $M_{d}$ is the design Mach number and $U_{c}$ is the convection speed of large turbulence structures. For a choked nozzle where the design Mach number is equal to unity the HarperBourne and Fisher's intensity formula is reproduced from these formulas. It should be noted, however, that Tam and Tanna's formula has been derived from the proposal that the broadband shock noise is generated by the weak interaction between the quasi-periodic shock cells and the downstream propagating large scale turbulence structures in the mixing layer of the jet. The agreement of Harper-Bourne and Fisher's and Tam and Tanna's formula, although they are built on different generation mechanism, appears to be due to the fact that both models describe the noise generated by the coherent scattering of sound sources. What is more instructional from 
these two models is that key parameters of the turbulence structures and the shock cell system associated with the broadband shock noise have been identified and widely studied.

The shock noise formula of Tam and Tanna is based on the vortex sheet shock cell model of Pack $^{7}$ which assumes that the mixing layer is thin and thus can be modelled by a vortex sheet. While this approximation is valid in the vicinity of the nozzle exit it is not accurate to compute the shock structure as the jet spreads downstream. A multiple scales shock cell model developed by Tam, Jackson, and Seiner ${ }^{8}$ accounts for the spreading of the mean flow and the shock cell structure is represented by a superposition of the wave guide modes of the jet flow. The predicted results, such as the shock cell spacing and the peak frequency, appear to be in better agreement with experimental results.

The shock noise generation mechanism proposed by Tam and Tanna was further elaborated in Tam's stochastic model theory. ${ }^{9}$ In this model the large turbulence structures are represented by a superposition of the intrinsic instability waves of the mean flow of the jet. Combined with the multiple scales shock cell model the theory predicts both the near and the far field noise spectra.

\section{Shock Noise Prediction Formulas}

The broadband shock associated noise prediction methods presented here are based on either Harper-Bourne and Fisher's model, Tam's stochastic model or are empirically based ones.

\section{(1) Harper-Bourne and Fisher's Prediction Formula (HBF, Ref. 2)}

Harper-Bourne and Fisher's point source array model leads to the following formulas for the sound power spectral density at an observer position $(R, \theta)$ :

$$
\begin{gathered}
\mathrm{G}_{\mathrm{p}}(\mathrm{R}, \theta, \omega)=\mathrm{G}_{0}(\mathrm{R}, \omega)\left[1+\sum_{\mathrm{i}=1}^{\mathrm{N}-1} \frac{2(\mathrm{~N}-\mathrm{i})}{\mathrm{N}} \mathrm{C}_{\mathrm{i}}(\omega) \sum_{\mathrm{s}=0}^{\mathrm{N}-(\mathrm{i}+1)} \cos \left\{\frac{\omega \mathrm{L}_{1}}{\mathrm{U}_{\mathrm{c}}}\left(1+\mathrm{M}_{\mathrm{c}} \cos \theta\right)\left(\mathrm{i}-\mu_{\mathrm{si}}\right)\right\}\right] \\
\mu_{\mathrm{si}}=\frac{\Delta \mathrm{L}}{\mathrm{L}_{1}}\left(\sum_{\mathrm{K}=0}^{\mathrm{i}} \mathrm{K}+\mathrm{is}\right)
\end{gathered}
$$

where $N$ corresponds to the number of shock cells, $L_{1}$ is the first shock cell spacing, and $\Delta L$ accounts for the unequal shock cell spacing by the formula, $\mathrm{L}_{n}=\mathrm{L}_{1}-(\mathrm{n}-1) \Delta \mathrm{L}$. HarperBourne and Fisher found $\mathrm{L}_{1}=1.31 \beta \mathrm{D}, \Delta \mathrm{L}=0.06 \mathrm{~L}_{1}$ from their choked jet experiment. $\mathrm{G}_{0}$ and $\mathrm{C}_{\mathrm{i}}$ in Eq. (5) correspond to the "group source spectrum" and "group average correlation coefficient" respectively and have been determined by Harper-Bourne and Fisher through a study of the choked jet noise spectra. The $1 / 3$ octave band sound pressure level is then computed by integrating the pressure spectrum over the bandwidth:

$$
\operatorname{SPL}\left(f_{c}\right)=\int_{f_{1}}^{f_{2}} G_{p} d f
$$


where $f_{c}, f_{1}, f_{2}$ correspond to the center, lower limit, and upper limit frequency of the bandwidth.

\section{(2) General Electric (GE)'s Prediction Formula (MGB, Ref. 11)}

Based on a correlation developed by Deneuville ${ }^{10}$ which includes some of the concepts of Harper-Bourne and Fisher's model, this method predicts the peak sound pressure level (SPL $\mathrm{S}_{\mathrm{p}}$ ) and the peak frequency $\left(f_{p}\right)$ for a specific observer position $(R, \theta)$ by

$$
\begin{aligned}
S P L_{p}=152.6 & +40 \log _{10}(\beta)+10 \log _{10}\left(A_{j} / R^{2}\right) \\
& +10 \log _{10}\left(D_{h} / D_{e q}\right)-40 \log _{10}\left(1-M_{f} \cos \theta\right)+10 \log _{10}(N / 8) \\
f_{p} & =\frac{U_{c}}{L\left(1+M_{c} \cos \theta\right)}
\end{aligned}
$$

where $D_{h}$ and $D_{e q}$ correspond to hydraulic and equivalent diameter and $A_{j}$ is the fully expanded jet area. $\mathrm{M}_{\mathrm{f}}$ denotes the flight Mach number, and the average shock cell spacing is $\mathrm{L}=1.1 \beta \mathrm{D}_{\mathrm{eq}}$. The recommended value for the number of shock cells (N) for conical nozzles is 8. Using these formulas the sound pressure level at any frequency is then calculated by

$$
\begin{aligned}
& \operatorname{SPL}(f)=S P L_{p}-10 \log _{10}\left(f / f_{p}\right), \quad f>f_{p} \\
& \operatorname{SPL}(f)=S P L_{p}+70 \log _{10}\left(f / f_{p}\right), \quad f<f_{p}
\end{aligned}
$$

\section{(3) Stone's Prediction Formula ${ }^{12}$}

This formula is based on the correlation of the empirical data for conical nozzle geometry, but some of the later findings such as the effect of a Mach disk formation at large shock strength parameter and C-D nozzle geometry effect have been incorporated. The formula which calculates the overall sound pressure level at $(R, \theta)$ is

$$
\begin{aligned}
\text { OASPL }=162+ & 10 \log _{10}\left[\left(\rho_{\infty} / \rho_{\text {ISA }}\right)^{2}\left(a_{\infty} / a_{I S A}\right)^{4}\right]+10 \log _{10}\left[\frac{\left(M_{j}^{2}-M_{d}^{2}\right)^{2}}{1+\left(M_{j}^{2}-M_{d}^{2}\right)^{2}}\right] \\
& +10 \log _{10}\left(\frac{A_{j}}{R^{2}}\right)-10 \log _{10}\left[1-M_{f} \cos \left(\theta+\theta_{a}\right)\right]+F\left(\theta-\theta_{M}\right)
\end{aligned}
$$

where ISA represents international standard atmosphere $(288 \mathrm{~K}$ and $101.3 \mathrm{kPa}), \theta_{\text {denotes }}$ the apparent angle of attack and $\theta_{M}$ is the Mach angle given by $\theta_{M}=180^{\circ}-\sin ^{-1}\left(1 / M_{j}\right)$. F is given by

$$
\mathrm{F}\left(\theta-\theta_{\mathrm{M}}\right)=0 \quad \text { for } \quad \theta \leq \theta_{M}, \quad \mathrm{~F}\left(\theta-\theta_{\mathrm{M}}\right)=-0.75 \text { for } \quad \theta>\theta_{\mathrm{M}}
$$


The 1/3-octave band sound pressure level is then calculated using the relationship in Table 1 where the nondimensional frequency parameter $S_{8}$ is given by

$$
\begin{aligned}
S_{s}=\left(\frac{f D}{k_{c} U_{j}}\right) \sqrt{\left|M_{j}^{2}-M_{d}^{2}\right|}\left[1-M_{f} \cos \left(\theta+\theta_{a}\right)\right] \\
\times \sqrt{\left[1+\left(\frac{k_{c} U_{j}}{a_{\infty}}\right) \cos \theta\right]^{2}+\alpha^{2} k_{c}^{2}\left(\frac{U_{j}}{a_{\infty}}\right)^{2}}
\end{aligned}
$$

where $k_{c}$ is the convection velocity factor (usually 0.7 ) and $\alpha$ is the turbulence length scale factor $(=0.2)$. For a convergent nozzle $M_{d}=1$.

\section{4) Tam's Formula for the Noise Power Spectrum}

Based on Tam's stochastic model theory the far field noise power spectral density at a point $(R, \theta)$ was obtained by $\operatorname{Tam}^{9}$ as

$$
\begin{aligned}
& \mathrm{S}(\mathrm{R}, \theta, \mathrm{f})= \frac{\mathrm{CL}_{\mathrm{w}}^{2}\left(\mathrm{M}_{\mathrm{j}}^{2}-\mathrm{M}_{\mathrm{d}}^{2}\right)^{2} \mathrm{~A}_{\mathrm{j}}}{\left(1+\frac{\gamma-1}{2} \mathrm{M}_{\mathrm{d}}^{2}\right)^{2} \mathrm{R}^{2}{ }^{2}{ }^{2} \mathrm{U}_{\mathrm{w}}^{2}} \\
& \\
& \times\left[\sum_{\mathrm{m}_{\mathrm{i}}=1}^{\infty} \frac{1}{\sigma_{\mathrm{m}}^{2}} \mathrm{e}^{-\left\{\left(\mathrm{f}_{\mathrm{m}} / \mathrm{f}\right)-1\right\}^{2}\left(\left(1+\mathrm{M}_{\mathrm{c}} \cos \theta\right)^{2} /\left(\mathrm{U}_{\mathrm{c}} / \mathrm{U}_{\mathrm{j}}\right)^{2}\right)\left(\mathrm{L}_{\mathrm{w}}^{2} / 2 \ln 2\right)}\right]
\end{aligned}
$$

where $C$ is an unknown constant and $L_{w}$ is the half-width of Tam's "similarity source model" and is related to the core length of the jet. Both parameters may be determined by fitting the prediction formula to experimental data. $A_{j}=\pi D_{j}^{2} / 4$ is the area of the fully expanded jet where the fully expanded jet diameter, $D_{j}$ is related to the nozzle exit diameter $D$ by the mass conservation equation as

$$
\frac{D_{j}}{D}=\left[\frac{1+\frac{\gamma-1}{2} M_{j}^{2}}{1+\frac{\gamma-1}{2} M_{d}^{2}}\right]^{(\gamma+1) / 4(\gamma-1)}\left(\frac{M_{d}}{M_{j}}\right)^{1 / 2}
$$

$\gamma$ is the specific heat ratio of the air, $\sigma_{\mathrm{m}}$ is the $\mathrm{m}^{\text {th }}$ root of the zeroth order Bessel function, and $f_{m}$ is defined by 


$$
f_{m}=U_{c} k_{m} /\left\{2 \pi\left(1+M_{c} \cos \theta\right)\right\}
$$

where $k_{m}$ corresponds to the wave number of $\mathrm{m}^{\text {th }}$ waveguide mode of shock cell structure at maximum wave amplitude. Note that this equation is equivalent to the peak frequency formula of Tam and Tanna introduced earlier in this paper.

Equation (13) was further modified by $\operatorname{Tam}^{13}$ to incorporate the hot jet effect,

$$
\begin{gathered}
\mathrm{S}(\mathrm{R}, \theta, \mathrm{f})=\frac{\overline{\mathrm{c}} \mathrm{L}_{\mathrm{w}}^{2} \mathrm{~A}_{\mathrm{j}} \overline{\mathrm{A}}^{2}}{\left(1+\frac{\gamma-1}{2} \mathrm{M}_{\mathrm{j}}^{2}\right) \mathrm{R}^{2} \frac{\rho_{\infty}^{2} \mathrm{a}_{\infty}^{4} \mathrm{M}_{\mathrm{j}}^{2}}{\mathrm{f}\left(\mathrm{fD}_{\mathrm{j}} / \mathrm{U}_{\mathrm{j}}\right)}} \\
\times\left[\sum_{\mathrm{m}=1}^{\mathrm{N}} \frac{1}{\sigma_{\mathrm{m}}^{2} \mathrm{~J}_{1}^{2}\left(\sigma_{m}\right)} \mathrm{e}^{\left.-\left(\left(\mathrm{f}_{\mathrm{m}} / \mathrm{f}\right)-1\right\}^{2}\left\{\left(1+\mathrm{M}_{\mathrm{c}} \cos \theta\right)^{2} /\left(\mathrm{U}_{\mathrm{c}} / \mathrm{U}_{\mathrm{j}}\right)^{2}\right\}\left(\mathrm{L}_{\mathrm{w}}^{2} / 2 \ln 2\right)\right]}\right.
\end{gathered}
$$

where $\bar{c}$ is again a constant equivalent to $\mathrm{C}$ in Eq. (13), $\mathrm{J}_{1}$ is the Bessel function of order one, and the quantity $\bar{A}^{2}$ characterizes the shock cell strength and has been semi-empirically determined to improve the original shock noise formula (Eq. (13)) to more extended off-design conditions.

$\operatorname{Tam}^{14}$ also derived a shock noise formula in flight by incorporating the source modification effect as well as the usual dynamic amplification effect,

$$
\begin{aligned}
& \mathrm{S}(\mathrm{R}, \theta, \mathrm{f})=\frac{\overline{\mathrm{c}} \mathrm{L}_{\mathrm{w}}^{2} \mathrm{~A}_{\mathrm{j}} \overline{\mathrm{A}}^{2}}{\left(1-\mathrm{M}_{\mathrm{f}}^{2} \sin ^{2} \theta\right) \mathrm{R}^{2}} \frac{\rho_{\infty}^{2} \mathrm{a}_{\infty}^{2} \mathrm{U}_{\mathrm{j}}^{2}}{\mathrm{f}\left(\mathrm{fD}_{\mathrm{j}} / \mathrm{U}_{\mathrm{j}}\right)} \\
& \times\left[\sum_{m=1}^{\infty} \frac{1}{\sigma_{m}^{2} J_{1}^{2}\left(\sigma_{m}\right)} e^{-\left\{\left(f_{m} / f\right)-1 \psi^{2}\left(\left(1+M_{c} \frac{M_{f}\left(1-M_{f}^{2} \sin ^{2} \theta\right)^{1 / 2}+\cos \theta}{\left(1-M_{f}^{2}\right)\left(1-M_{f}^{2} \sin ^{2} \theta\right)^{1 / 2}}\right)^{2} /\left(U_{c} / U_{j}\right)^{2}\right)\left(L_{w}^{2} / 2 \ln 2\right)\right.}\right]
\end{aligned}
$$


where

$$
f_{m}=\frac{U_{c} k_{m} /(2 \pi)}{1+M_{c} \frac{M_{f}\left(1-M_{f}^{2} \sin ^{2} \theta\right)^{1 / 2}+\cos \theta}{\left(1-M_{f}^{2}\right)\left(1-M_{f}^{2} \sin ^{2} \theta\right)^{1 / 2}}}
$$

In these formulas the coordinate system was fixed at the nozzle exit and thus the relative motion between the source and the observer was not accounted for. Since flight data are measured for the radiation angle $\left(\theta_{r}\right)$ and distance $\left(R_{r}\right)$, the equivalent geometric angle $\left(\theta_{m}\right)$ and distance $\left(R_{m}\right)$ have to be inserted for using these formulas. These quantities are related by $\tan \theta_{m}=\sin \theta_{r} /\left(\cos \theta_{r}-M_{f}\right)$ and $R_{m}=R_{r} \sin \theta_{r} / \sin \theta_{r}$. Also, the right hand side of Eq. (18) has to be divided by $\left(1-\mathrm{M}_{\mathrm{f}} \cos \theta_{\mathrm{r}}\right)$ to incorporate Doppler frequency shift.

Another formula was obtained by $\operatorname{Tam}^{14}$ to simulate the flight effect in open wind tunnel experiment (i.e., free jet) and is given by

$$
\begin{aligned}
& \mathrm{S}(\mathrm{R}, \theta, \mathrm{f})=\frac{4 \overline{\mathrm{c}} \mathrm{L}_{\mathrm{w}}^{2} \mathrm{~A}_{\mathrm{j}} \overline{\mathrm{A}}^{2}}{\mathrm{R}^{2}} \frac{\rho_{\infty}^{2} \mathrm{a}_{\infty}^{2} \mathrm{U}_{\mathrm{j}}^{2}}{\mathrm{f}\left(\mathrm{fD}_{\mathrm{j}} / \mathrm{U}_{\mathrm{j}}\right)} \\
& \quad \times\left[\sum_{\mathrm{m}=1}^{\infty} \frac{1}{\sigma_{\mathrm{m}}^{2} \mathrm{~J}_{1}^{2}\left(\sigma_{\mathrm{m}}\right)} \mathrm{e}^{-\left\{\left(\overline{\left.\left.\mathrm{f}_{\mathrm{m}} / \mathrm{f}\right)-1\right\}^{2}\left\{\left(1-\beta_{\mathrm{s}} \mathrm{U}_{\mathrm{c}} / \mathrm{a}_{\infty}\right)^{2} /\left(\mathrm{U}_{\mathrm{c}} / \mathrm{U}_{\mathrm{j}}\right)^{2}\right\}\left(\mathrm{L}_{\mathrm{w}}^{2} / 2 \ln 2\right)}\right]\right.}\right. \\
& \times\left\{\left|\left(\rho_{\mathrm{T}} / \rho_{\infty}\right)\left(1-\beta_{\mathrm{s}} \mathrm{M}_{\mathrm{T}} \mathrm{a}_{\mathrm{T}} / \mathrm{a}_{\infty}\right)^{2}\right| \beta_{\mathrm{s}}^{2}-\left.1\right|^{1 / 2} / \alpha_{\mathrm{g}}+\left.1\right|^{2} \alpha_{\mathrm{s}} \overline{\mathrm{F}} \sin \theta\right\}^{-1}
\end{aligned}
$$

where $\beta_{\mathrm{s}}$ is the root of the equation

$$
\begin{aligned}
{\left[\frac{\mathrm{a}_{\mathrm{T}} \beta_{\mathrm{s}}}{\mathrm{a}_{\infty}}+\left(1-\frac{\beta_{\mathrm{s}} \mathrm{M}_{\mathrm{T}}^{\mathrm{a}_{\mathrm{T}}}}{\mathrm{a}_{\infty}}\right) \mathrm{M}_{\mathrm{T}}\right] } & {\left[\left(\frac{\mathrm{a}_{\mathrm{T}} \beta_{\mathrm{s}}}{\mathrm{a}_{\infty}}\right)^{2}-\left(1-\frac{\beta_{\mathrm{s}} \mathrm{M}_{\mathrm{T}} \mathrm{a}_{\mathrm{T}}}{\mathrm{a}_{\infty}}\right)^{2}\right]^{-1 / 2} \frac{\mathrm{R}_{\mathrm{T}}}{\mathrm{r}} \sin \theta } \\
& +\beta_{\mathrm{s}}\left(1-\frac{\mathrm{R}_{\mathrm{T}}}{\mathrm{r}}\right) \sin \theta\left(\beta_{\mathrm{g}}^{2}-1\right)^{-1 / 2}+\mathrm{i} \cos \theta=0
\end{aligned}
$$


and

$$
\begin{aligned}
& \alpha_{\mathrm{s}}=\left|\beta_{\mathrm{s}}^{2}-\left(1-\frac{\beta_{\mathrm{s}} \mathrm{M}_{\mathrm{T}} \mathrm{a}_{\mathrm{T}}}{\mathrm{a}_{\infty}}\right)^{2}\left(\frac{\mathrm{a}_{\infty}}{\mathrm{a}_{\mathrm{T}}}\right)^{2}\right|^{1 / 2} \\
& \overline{\mathrm{F}}=\left|\left(\mathrm{R}_{\mathrm{T}} / \mathrm{r}\right)\left(\mathrm{a}_{\mathrm{co}_{0}} / \mathrm{a}_{\mathrm{T}}\right)^{2} / \alpha_{\mathrm{s}}{ }^{3}+\left(1-\mathrm{R}_{\mathrm{T}} / \mathrm{r}\right) /\left(\beta_{\mathrm{s}}^{2}-1\right)^{3 / 2}\right| \sin \theta \\
& \bar{f}_{m}=\frac{\frac{U_{c} k_{m}}{(2 \pi)}}{1-\frac{\beta_{s} U_{c}}{a_{\infty}}}
\end{aligned}
$$

and $\mathrm{R}_{\mathrm{T}}, \mathrm{a}_{\mathrm{T}}, \rho_{\mathrm{T}}$ correspond to the open wind tunnel radius, speed of sound, and density respectively. In Eqs. (19), (20), and (22) of Tam's original paper, ${ }^{14}$ several typographical errors were found and these were corrected in present paper through a discussion with Tam.

\section{Experimental Data}

Nozzle geometries chosen for the comparison include convergent and convergent-divergent, axisymmetric nozzles. These nozzles have been tested by General Electric (GE) for NASA Lewis Research Center and test results were reported in Ref. 15. The test data were obtained in GE's anechoic free jet facility. Reported diameters of the nozzles are 5.094 in. for the convergent nozzle and 5.1 in. for the convergent-divergent nozzle. The acoustic data are corrected to a distance of $40 \mathrm{ft}$ away from the nozzle exit. The total jet temperature were between 1700 and $1750 \mathrm{R}$. In order to investigate the flight effect on the noise characteristics the distinction has to be made between the free jet flight data and the real flight data. Since the real flight data is rare GE's flight-transformed data has been used for comparison. These data are corrected from the data measured in the free jet facility by removing refraction and turbulence absorption effects and incorporating the dynamic effect as well as the Doppler frequency shift. Details of the correction procedure may be found in Ref. 15. GE's test conditions are close to the design pressure ratios and thus there are possibilities that some of the noise data may include a substantial contribution from the turbulence mixing noise, even in the forward quadrant region where broadband shock associated noise is known to be dominant. When this happens the comparison between data and prediction may not be meaningful. To estimate the contribution from the turbulence mixing noise Stone's mixing noise prediction formula ${ }^{16}$ has been adopted and the results are also included in the comparison. As will be shown later it turned out that the mixing noise contribution was very substantial for the convergent-divergent nozzle geometry at GE's test conditions. Accordingly, to validate the prediction formulas for more severe off-design con-

ditions NASA Langley data ${ }^{17}$ have been also used. These data were measured at Langley's anechoic chamber and microphones were $12 \mathrm{ft}$ away from the nozzle exit. The convergent-divergent nozzle of which noise data are used here for comparison has the exit diameter of $1.68 \mathrm{in}$. and 
design pressure ratio of 3.67 . Although these data were obtained only for cold jet flow and static case they appear to be sufficient for the purpose of comparison. To investigate the capabilities of prediction formulas in incorporating temperature effect, Lockheed data ${ }^{18}$ are used. These data were obtained at Lockheed's anechoic room and microphones were $12 \mathrm{ft}$ away from the nozzle exit. Tested nozzle is a convergent nozzle with the exit diameter of 2 in.

\section{$\underline{\text { Results and Comparison }}$}

Having summarized several broadband shock noise prediction formulas and available experimental data what follows next is a comparison of the noise field calculated by these formulas with data. Spectral densities produced by HBF and Tam's formulas are integrated to convert to standard 1/3-octave form so that the predictions can be compared with jet noise test data.

\section{(1) Convergent Nozzle; Static Case}

Test conditions chosen for the comparison are for the nozzle pressure ratios of 2.87 and 3.32 and results are depicted on Figs. 1 and 2. The $1 / 3$ octave band sound pressure level computed by each of four formulas is compared with data at observer angles with respect to the inlet axis of $40^{\circ}, 70^{\circ}$, and $100^{\circ}$. In general, with the exception of the angle at $100^{\circ}$, all four methods predict the peak frequency reasonably well and the discrepancy in the sound pressure level is within $5 \mathrm{~dB}$. Tam's formula generates a substantial drop right beyond the peak especially at shallow inlet angles and $\mathrm{Tam}^{9}$ speculates that the unsteady nature of the shock cell structure has to be accounted for to improve the model. The contribution from the turbulence mixing noise appears to be far from being negligible at the observer angle of $70^{\circ}$ and its dominance over the shock noise is obvious at the observer angle of $100^{\circ}$. At the low frequency region below the peak, predicted spectra do not show a good agreement with data. Considering that low frequency region would be dominated by the mixing noise for a full-scale nozzle this doesn't appear to be a big issue.

\section{(2) Convergent-Divergent Nozzle; Static Case}

Both overexpanded and underexpanded conditions are compared for a convergent-divergent nozzle for a design pressure ratio of 3.12. Two off-design pressure ratios of 2.87 and 3.31 are considered and results at the observer angles of $40^{\circ}, 70^{\circ}$, and $100^{\circ}$ are depicted on Figs. 3 and 4. Since MGB and HBF are not directly applicable for the convergent-divergent nozzle geometry, only Stone's and Tam's formulas are compared with data. Although Tam's formula provides a good estimate of the peak frequency at the observer angle of $40^{\circ}$ the noise data is basically dominated by the turbulence mixing noise at all angles and thus the comparison cannot produce any meaningful interpretation. It appears that two off-design conditions tested by GE are relatively small deviations from the design condition so that the contribution of the shock noise is not strong enough to dominate the noise field, even at shallow observer angles.

As mentioned earlier, data for more severe off-design conditions are available from NASA Langley test. ${ }^{17}$ Depicted on Fig. 5 is the comparison at the observer angle of $45^{\circ}$ for three different pressure ratios of $2.7,5.77$, and 7.7. The design pressure ratio here is 3.69 , and note that the mixing noise contribution is minimal. Although the agreement is not as good as the convergent nozzle case both formulas show a reasonable agreement with data with the exception of the substantial drop after the peak in Tam's prediction. A possible explanation for the better agreement with the convergent nozzle is that all the prediction methods include some form of empirical input derived from convergent nozzle data which may not be equally suitable for a dif- 
different nozzle geometry. With regard to the peak frequency it is observed that Tam's formula shows little difference of peak frequency between convergent and convergent-divergent nozzles at the same pressure ratio and observer angle (compare Fig. 1(a) with Fig. 3(a) and Fig. 2(a) with Fig. 4(a)). Considering that the peak frequency appears to be better predicted by Tam's formula it can be speculated that the design Mach number has little effect on the peak frequency of the shock noise. On the other hand, Stone's formula produces a large shift of peak frequency for different nozzle geometries. Since the peak frequency of Stone's formula is directly related to the nondimensional frequency parameter $S_{s}$ given by Eq. (12), we suggest $M_{j}^{2}-M_{d}^{2}$ in Eq. (12) be changed to $\mathrm{M}_{\mathrm{j}}^{2}-1$. As depicted on Fig. 6 this slight modification provides a much better agreement of peak frequency with test data.

\section{(3) Convergent Nozzle; Flight Case}

As mentioned earlier GE's test data for the flight case is taken in their free jet facility and then corrected to simulate the real flight data. These corrected data (flight transformed data) have been directly compared with predictions. Depicted on Fig. 7 is the comparison for two different pressure ratios of 2.88 and 3.32 at observer angle of $40^{\circ}$. The free stream speed is $400 \mathrm{ft} / \mathrm{s}$, which corresponds to the Mach number of 0.35 at the test condition. According to Fig. 7, MGB and HBF predict the peak frequency and sound pressure level better than Stone and Tam. Tam underpredicts the peak frequency while Stone overpredicts. Especially at the pressure ratio of 3.32, Tam's predicted sound pressure level is substantially below the data in most of the frequency range. At present there is not enough experimental evidence to clarify these discrepancies and real flight data base is desired. In passing it should be noted that the flight transformed data are not directly measured data in a real flight situation and the discrepancy between the prediction and the data may be possibly attributed to GE's transformation procedure itself. This speculation appears to be supported by the comparison between Tam's free jet predictions and the uncorrected free jet data as shown on Fig. 8. For the same pressure ratios and the observer angle the agreement is much better than previous comparison with the flight transformed data. Excluding the sudden drop of the level after the peak both the sound pressure level amplitude and the peak frequency are reasonably predicted. Compared with the static case both the prediction and the data exhibit a slight decrease of peak frequency and this is in agreement with the test results of Brown et al. ${ }^{19}$ and Norum and Shearin. ${ }^{20}$

As discussed earlier GE's noise data for the convergent-divergent nozzle geometry is masked by the turbulence mixing noise at most observer angles and thus any comparison between the prediction and data cannot be made for the flight case either. It is speculated, however, that similar characteristics observed in convergent nozzle, flight case will be applied here.

\section{(4) Effect of Temperature}

Estimating the effect of the temperature on the shock noise is not straightforward since turbulence mixing noise becomes more dominant as the jet temperature increases. After computing the mixing noise using Stone's formula it appears that Lockheed's data ${ }^{18}$ at the observer angle of $45^{\circ}$ has little contribution from mixing noise and thus were used for the investigation of the temperature effect on the shock noise. These data were obtained for the convergent nozzle, static conditions. Figure 9 shows comparison of predicted results with Lockheed data at four different jet temperature ratios of $T_{j} / T_{\infty}=0.623,0.996,1.811$, and $2.248 . T_{j}$ and $T_{\infty}$ are the fully expanded static jet and the ambient temperatures and the nozzle pressure ratio is fixed at $P R=4.73$. Note that $T_{j} / T_{\infty}=0.623$ corresponds to the cold jet case. For cold jet case in Fig. 9(a), MGB and HBF overestimate the shock noise magnitude while Stone's and Tam's 
predictions produce a reasonable agreement except at the peak frequency region. This observation appears to be reversed for hot jet cases as shown in Figs. 9(b), (c), and (d). Here MGB and HBF show better agreement with data. In order to better understand these inconsistent agreement the temperature effect on the data and predictions was separately plotted in Figs. 10(a) and (b). From cold jet to hot jet data in Fig. 10(a) the peak frequency as well as the sound pressure level has increased. The increase of sound pressure level by almost $5 \mathrm{~dB}$ is especially noteworthy since other test results ${ }^{3,4}$ showed that the shock noise levels are essentially independent of jet temperature. In Ref. 18, Lockheed also developed their own shock noise predictions which showed a good agreement with both cold and hot jet data. Although their prediction formulas are basically identical to HBF, slight modifications were made to account for the temperature effect. Figure 10(b) shows the temperature effect predicted by HBF. Here, the peak frequency increases from cold to hot jet case but the shock noise levels essentially stay the same. Similar characteristics are predicted by other prediction formulas.

\section{Summary and Conclusion}

This study reviews the current status of broadband shock noise prediction methods. The shock noise generated by supersonic jets is predicted in formulas by Harper-Bourne and Fisher (HBF), Stone, General Electric (MGB), and Tam. Test data from GE, NASA Langley, and Lockheed are used for comparison with predictions. Only data where shock noise clearly dominates other sources such as mixing noise are used. The nozzle geometry selected for the comparison consists of a convergent and convergent-divergent, both axisymmetric, nozzles. Since HBF and MGB cannot provide direct predictions for the convergent-divergent nozzle geometry only Stone's and Tam's formulas were compared with corresponding data.

All four prediction formulas give a reasonable agreement with the measured data for the static, convergent nozzle case except some local, minor differences. Stone's and Tam's predictions for the static, convergent-divergent nozzle case are not as good as the convergent nozzle predictions. A possible reason for the better agreement with the convergent nozzle is attributed to empirical inputs in the formulas derived from convergent nozzle data which may not be equally applicable to a different nozzle geometry.

Predicted spectra for nozzles in flight show larger discrepancies from the flight-simulated data. This may be in part due to correction procedures applied to the test data measured in the free jet facility. In general, HBF and MGB were somewhat better in predicting shock noise in flight. Comparison between Tam's predictions and uncorrected free jet flight data shows much better agreement.

To investigate the capability of prediction formulas in incorporating the jet temperature effect, predicted results were compared with Lockheed data and a favorable agreement was observed.

Summarizing the current capabilities and limitations of the shock noise prediction methods, most formulas provide a good estimate of shock noise component for an axisymmetric nozzle geometry under the static condition but extension of the prediction capability to a different geometry or a flight case is still limited or mostly qualitative. Considering that the candidate nozzle geometry for the HSCT engine will be a much more complicated one, current formulas have to be greatly improved to account for various nozzle geometries. 
The effect of flight on the shock noise characteristics is another important area for future research. Current data base for the flight case is mostly obtained from flight simulated facilities and since the real flight data is very difficult to obtain, a reliable transformation procedure to convert the flight simulated data into a real flight data has to be developed and verified.

In order to modify or improve empirically derived inputs in current prediction methods, computational fluid dynamics sheds a bright spot for the future direction of the subject. There are several computational programs which provide a good estimate of the jet aerodynamics as well as reasonable shock capturing capabilities. A substantial amount of computational efforts is being emphasized at NASA Lewis to predict the supersonic jet flow field for comparison with available experimental data. With a better understanding of the shock aerodynamics it appears that some of the important questions raised in this survey will be clarified.

\section{$\underline{\text { References }}$}

1. Tam, C.K.W., "On Broadband Shock Associated Noise of Supersonic Jets," Recent Advances in Aeroacoustics, A. Krothapalli, and C.A. Smith, eds., Springer-Verlag, New York, 1986, pp. 25-51.

2. Harper-Bourne, M., and Fisher, M.J., "The Noise from Shock Waves in Supersonic Jets," Noise Mechanisms, AGARD CP-131, AGARD, Neuilly-Sur-Seine, France, 1973, pp. 11-1 to 11-13.

3. Tanna, H.K., "An Experimental Study of Jet Noise, Part II; Shock Associated Noise," Journal of Sound and Vibration, Vol. 50, 1977, pp. 429-444.

4. Tam, C.K.W. and Tanna, H.K., "Shock Associated Noise of Supersonic Jets from Convergent-Divergent Nozzles," Journal of Sound and Vibration, Vol. 81, 1982, pp. 337-358.

5. Seiner, J.M. and Norum, T.D., "Aerodynamic Aspects of Shock Containing Jet Plumes," AIAA Paper 80-0965, June 1980.

6. Powell, A., "On the Mechanism of Choked Jet Noise," Proceedings of the Physical Society of London Section B, Vol. 66, 1953, pp. 1039-1056.

7. Pack, D.C., "A Note on Prandtl's Formula for the Wavelength of a Supersonic Gas Jet," Quarterly Journal of Mechanics and Applied Mathematics, Vol. 3, 1950, pp. 173-181.

8. Tam, C.K.W., Jackson, J.A., and Seiner, J.M., "A Multiple-Scales Model of the Shock-Cell Structure of Imperfectly Expanded Supersonic Jets," Journal of Fluid Mechanics, Vol. 153, 1985, pp. 123-149.

9. Tam, C.K.W., "Stochastic Model Theory of Broadband Shock Associated Noise from Supersonic Jets," Journal of Sound and Vibration, Vol. 116, 1987, pp. 265-302.

10. Deneuville, P., "Prevision Simplifiee du Bruit d'Ondes de Choc d'un Jet Supercritique de Tuyere Convergente," SNECMA YKA No. 5982/76, Societe Nationale d'Etude et de Construction de Moteurs d'Avion, France, 1976. 
11. Mani, R., et al., "High Velocity Jet Noise Source Location and Reduction, Task 2-Theoretical Developments and Basic Experiments," FAA-RD-76-79-2, May 1977. (Avail. NTIS, AD-A094291.)

12. Stone, J.R., "Supersonic Jet Shock Noise Reduction," AIAA Paper 84-2278, Oct. 1984 (also, NASA TM-83799).

13. Tam, C.K.W., "Broadband Shock-Associated Noise of Moderately Imperfectly Expanded Supersonic Jets," Journal of Sound and Vibration, Vol. 140, 1990, pp. 55-71.

14. Tam, C.K.W., "Forward Flight Effects on Broadband Shock Associated Noise of Supersonic Jets," AIAA Paper 89-1088, Apr. 1989.

15. Yamamoto, K., et al., "Experimental Investigation of Shock-Cell Noise Reduction for Single Stream Nozzles in Simulated Flight, Comprehensive Data Report, Vol. 1; Test Nozzles and Acoustic Data," NASA CR-168234, 1984.

16. Stone, J.R., and Montegani, F.J., "An Improved Prediction Method for the Noise Generated in Flight by Circular Jets," NASA TM-81470, 1980.

17. Norum, T.D. and Seiner, J.M., "Measurements of Mean Static Pressure and Far-Field Acoustics of Shock-Containing Supersonic Jets," NASA TM-84521, 1982.

18. Tester, B.J., et al., "The Generation, Radiation and Prediction of Supersonic Jet Noise, Vol. 1," AFAPL-TR-78-85-VOL-1, 1978. (Avail. NTIS, AD-A065020.)

19. Brown, W.H., Ahuja, K.K. and Tam, C.K.W., "High Speed Flight Effects on Shock Associated Noise," AIAA Paper 86-1944, July 1986.

20. Norum, T.D. and Shearin, J.G., "Shock Structure and Noise of Supersonic Jets in Simulated Flight to Mach 0.4," NASA TP-2785, 1988. 
TABLE 1.-RECOMMENDED SPECTRUM FOR SHOCK NOISE

[Stone, Ref. 16.]

\begin{tabular}{|c|c|c|c|}
\hline $\begin{array}{c}\text { Frequency } \\
\text { parameter, } \\
\log \mathrm{S}_{\mathrm{s}}\end{array}$ & $\begin{array}{c}\text { Relative level } \\
\text { SPL-OASPL, } \\
\mathrm{db}\end{array}$ & $\begin{array}{c}\text { Frequency } \\
\text { parameter, } \\
\log \mathrm{S}_{\mathrm{g}}\end{array}$ & $\begin{array}{c}\text { Relative level } \\
\text { SPL-OASPL, } \\
\mathrm{db}\end{array}$ \\
\hline-1.8 & -94.6 & 0.1 & -8.6 \\
-1.7 & -89.6 & .2 & -9.6 \\
-1.6 & -84.6 & .3 & -10.6 \\
-1.5 & -79.6 & .4 & -11.6 \\
-1.4 & -74.6 & .5 & -12.6 \\
-1.3 & -69.6 & .6 & -13.6 \\
-1.2 & -64.6 & .7 & -14.6 \\
-1.1 & -59.6 & .8 & -15.6 \\
-1.0 & -54.6 & .9 & -16.6 \\
-.9 & -49.6 & 1.0 & -17.6 \\
-.8 & -44.6 & 1.1 & -18.6 \\
-.7 & -39.6 & 1.2 & -19.6 \\
-.6 & -34.6 & 1.3 & -20.6 \\
-.5 & -29.6 & 1.4 & -21.6 \\
-.4 & -24.6 & 1.5 & -22.6 \\
-.3 & -19.6 & 1.6 & -23.6 \\
-.2 & -14.6 & 1.7 & -24.6 \\
-.1 & -9.6 & 1.8 & -25.6 \\
0 & -7.6 & & \\
\hline
\end{tabular}




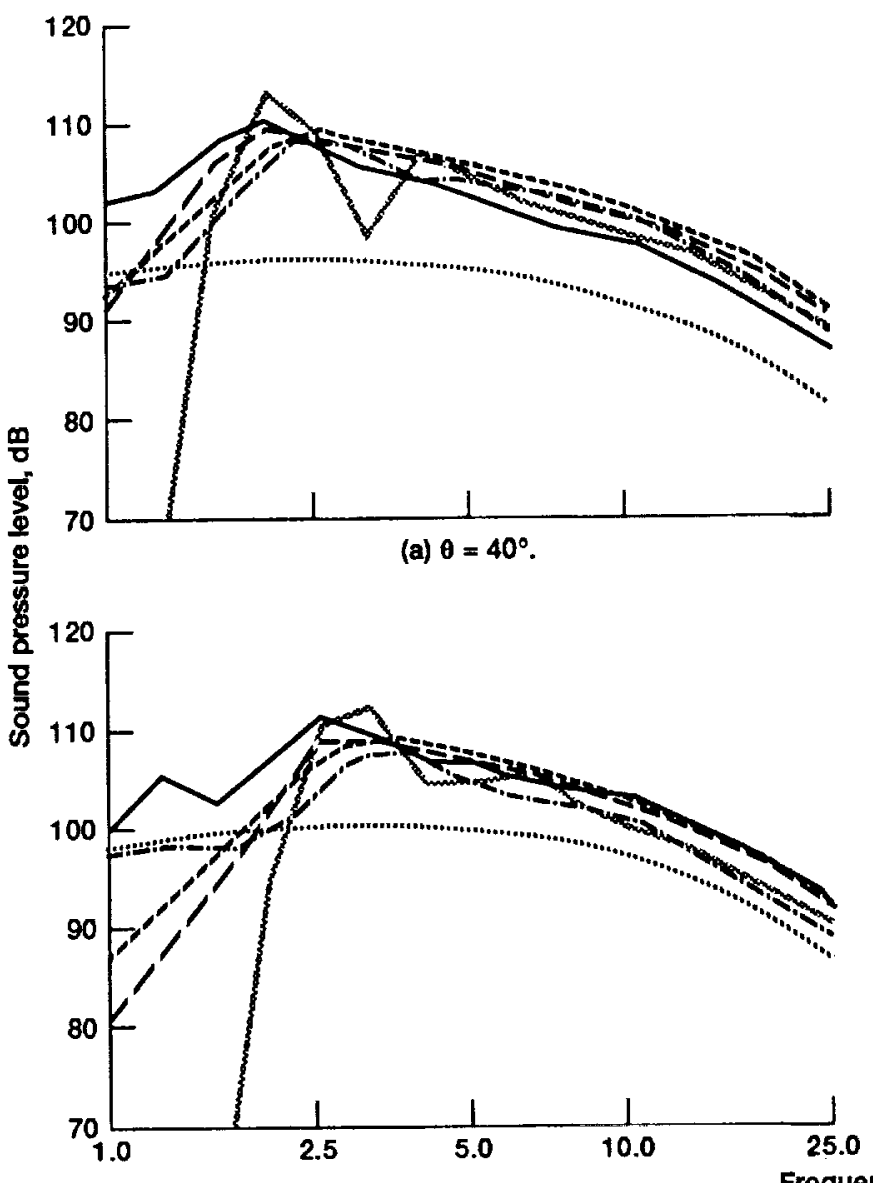

(b) $\theta=70^{\circ}$.

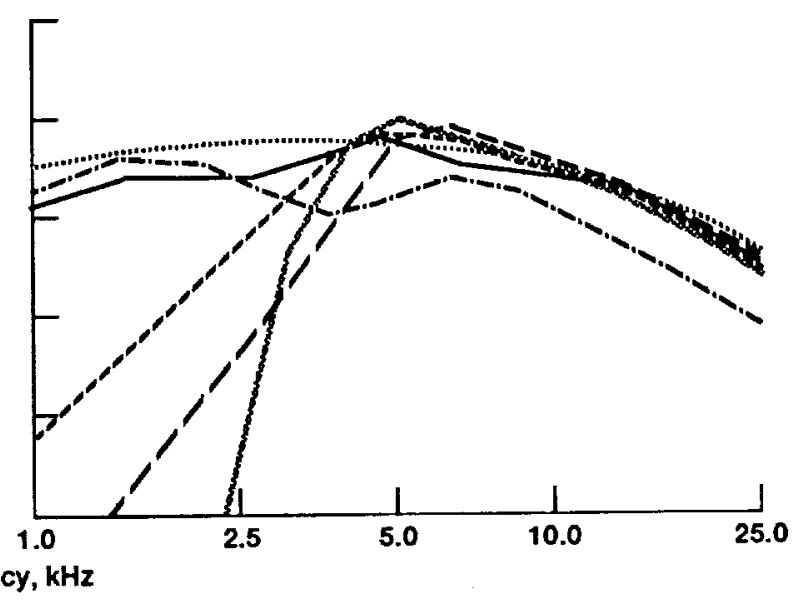

(c) $\theta=100^{\circ}$.

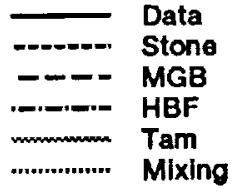

Figure 1.-Predicted and measured spectra for a convergent nozzle, static conditions, $(P R=2.87)$. 


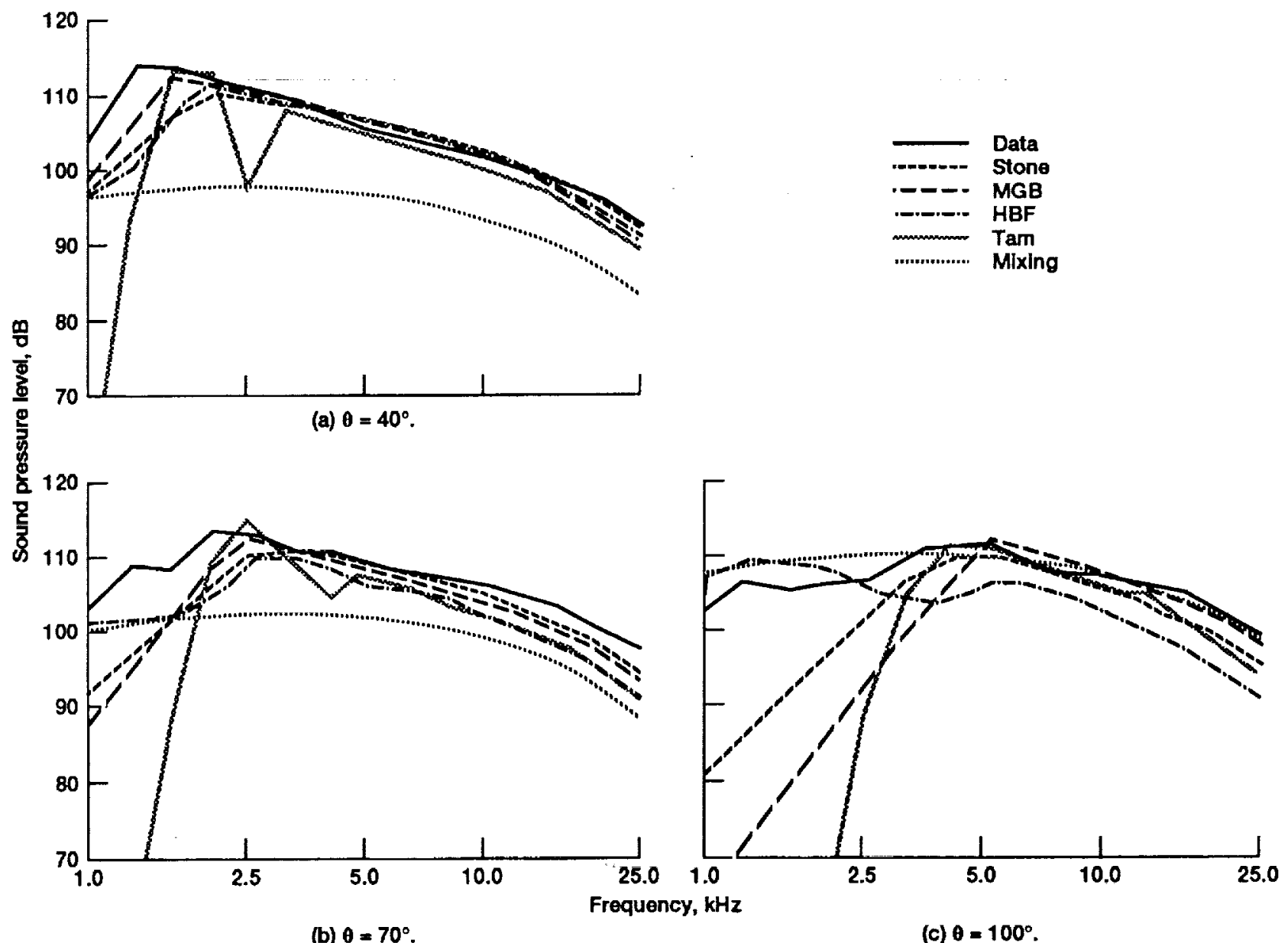

Flgure 2.-Predlcted and measured spectra for a convergent nozzle, static conditions, $(P R=3.32)$. 


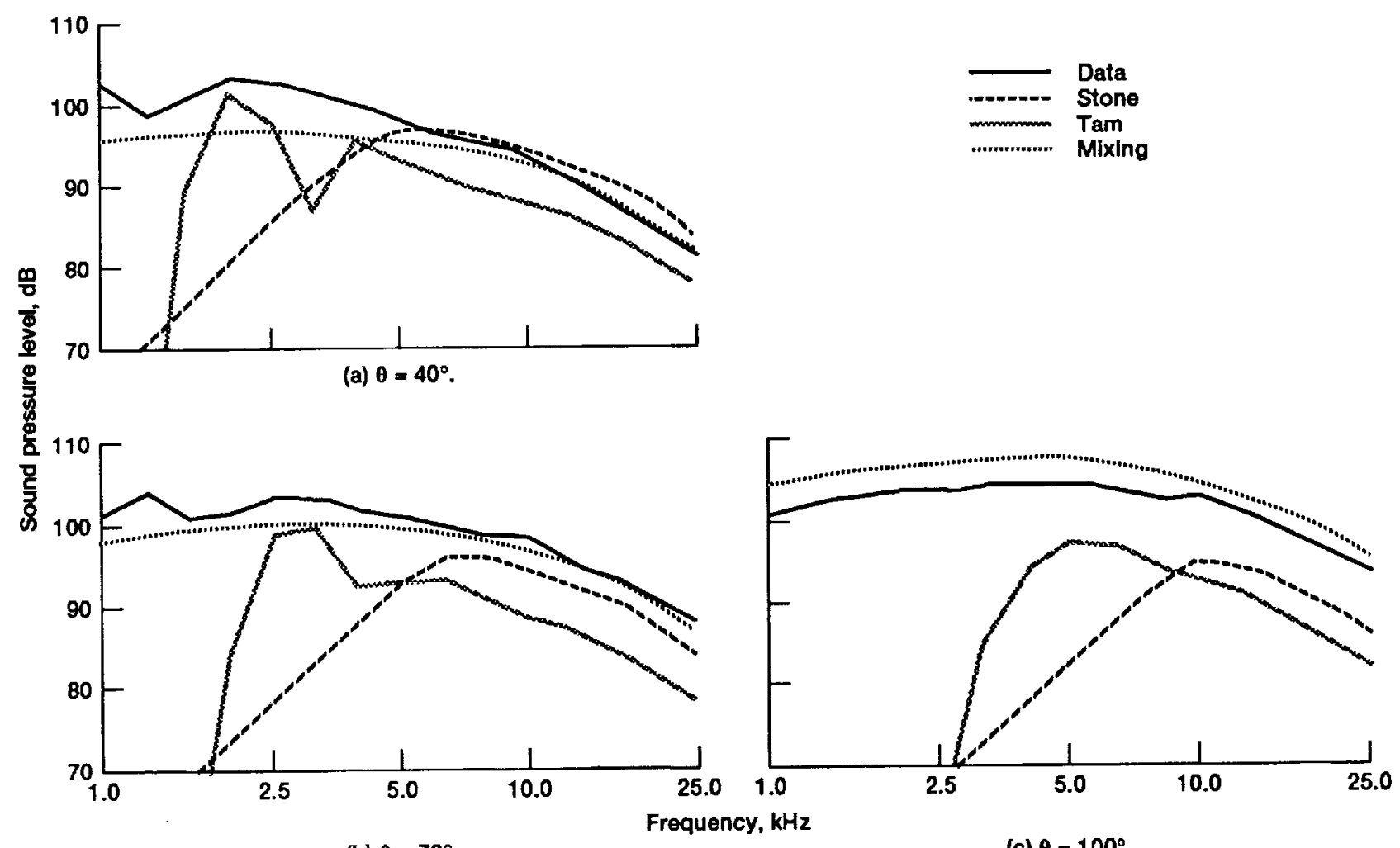

(b) $0=70^{\circ}$.

(c) $\theta=100^{\circ}$.

Figure 3.-Predicted and measured spectra for a convergent-divergent nozzle, static conditions $(P R=2.87, D P R=3.12)$. 


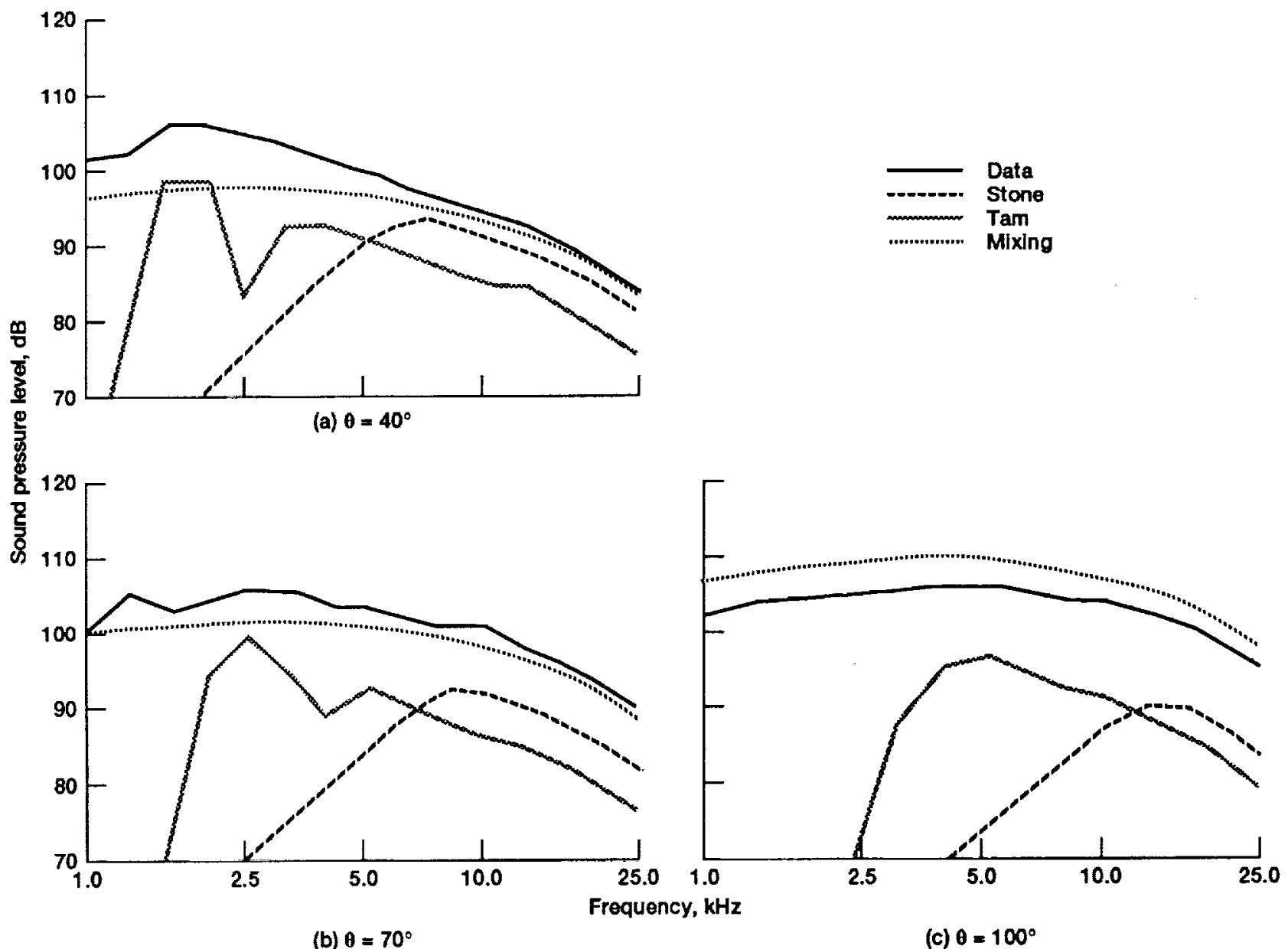

(b) $\theta=70^{\circ}$

(c) $\theta=100^{\circ}$

Figure 4.-Predicted and measured spectra for a convergent-divergent nozzle, static conditions (PR $=3.31, D P R=3.12$ ). 


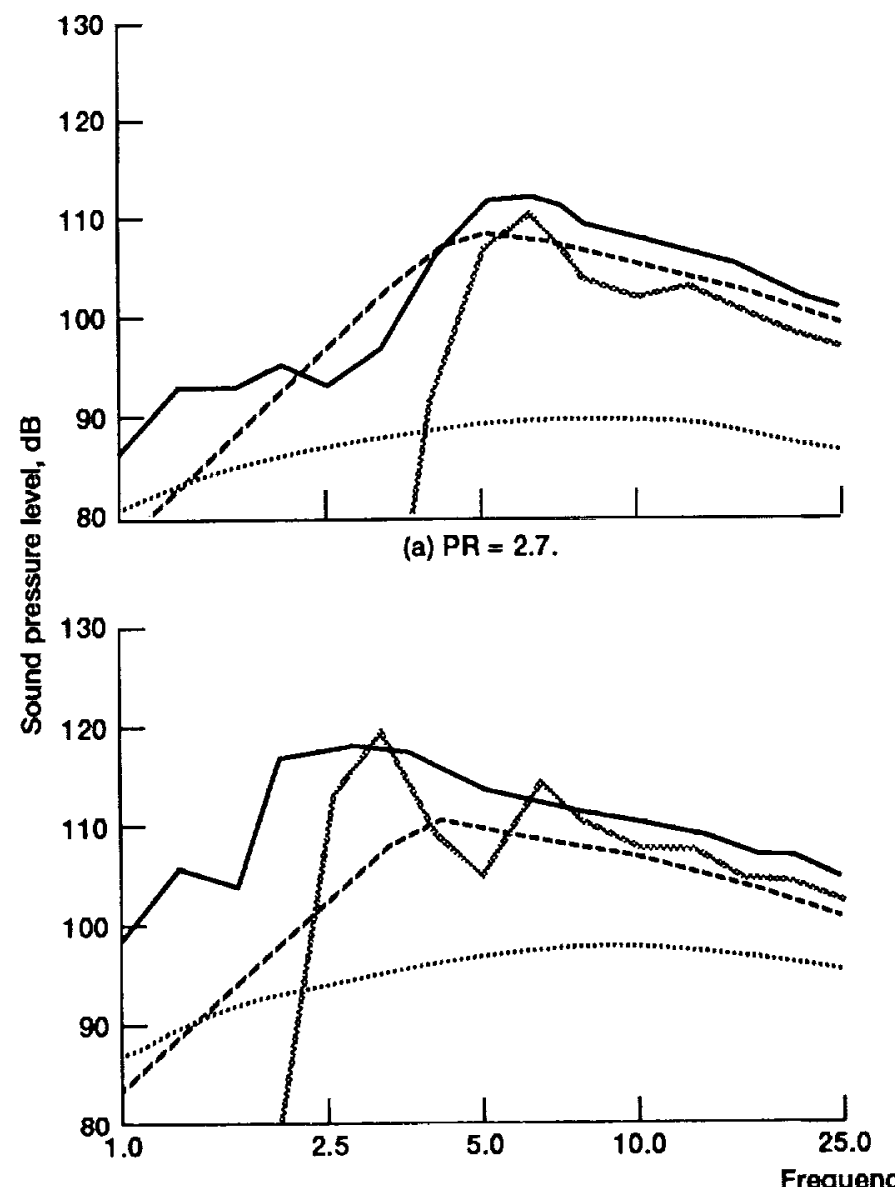

(b) $\mathrm{PR}=\mathbf{5 . 7 7}$
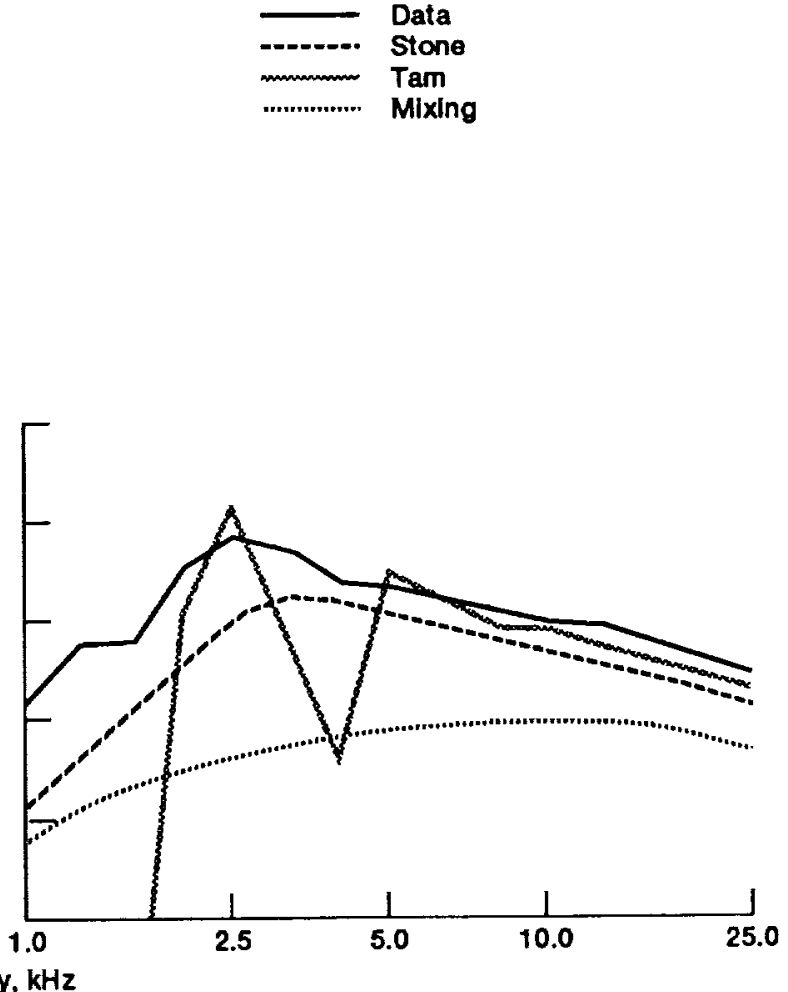

(c) $P R=7.7$.

Figure 5.-Predicted and measured spectra for a convergent-divergent nozzle, static conditions (DPR $=3.67, \theta=45^{\circ}$ ). 


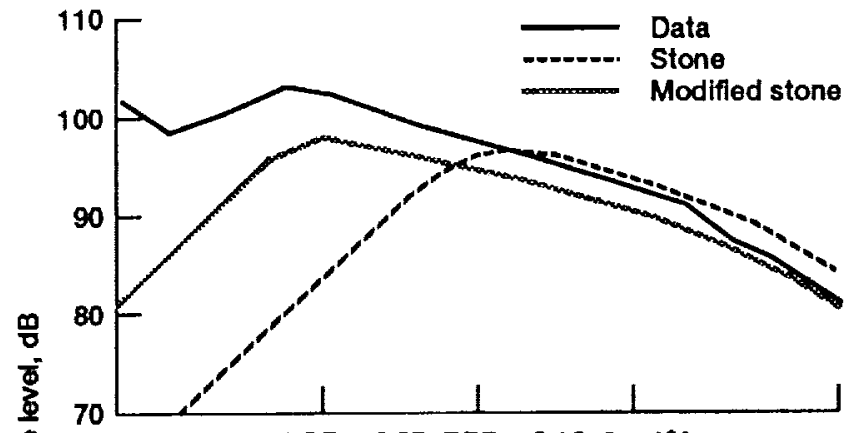

(a) $P R=2.87, D P R=3.12, \theta=40^{\circ}$.

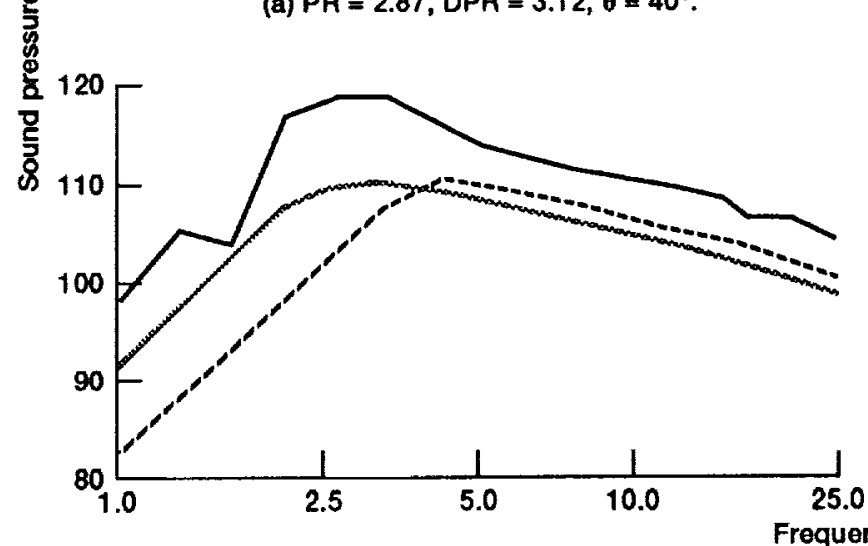

(c) $P R=5.77, D P R=3.67, \theta=45^{\circ}$.

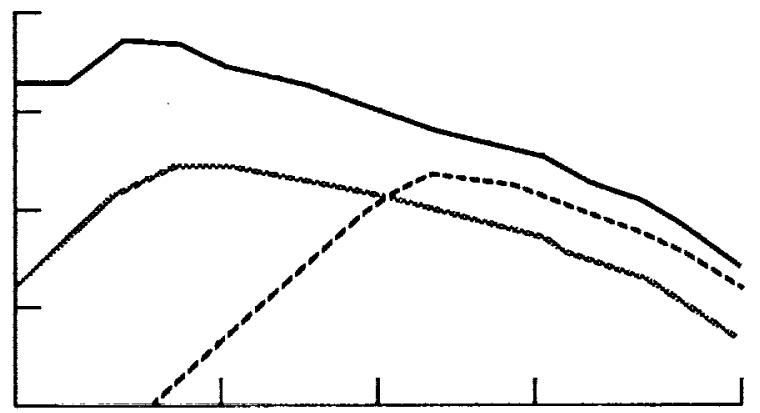

(b) $P R=3.31, D P R=3.12, \theta=40^{\circ}$.

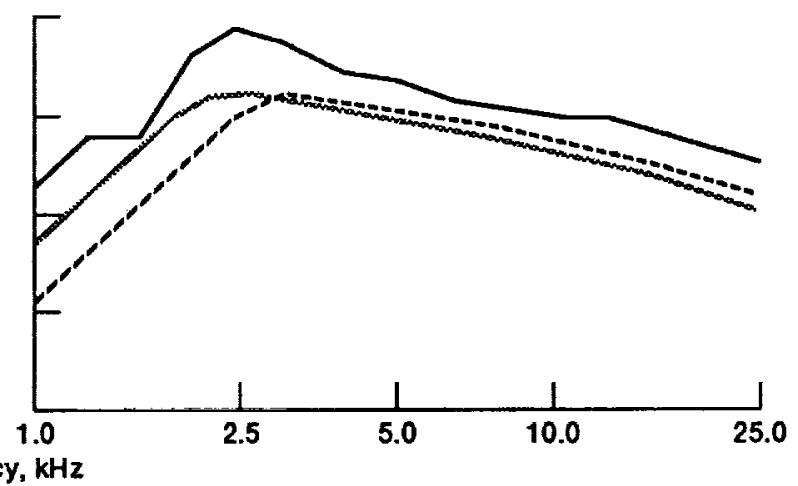

(d) $P R=7.7, D P R=3.67, \theta=45^{\circ}$.

Figure 6.-Comparison of the original stone's formula with the modified stone's formula for a convergent-divergent nozzle, static conditions.

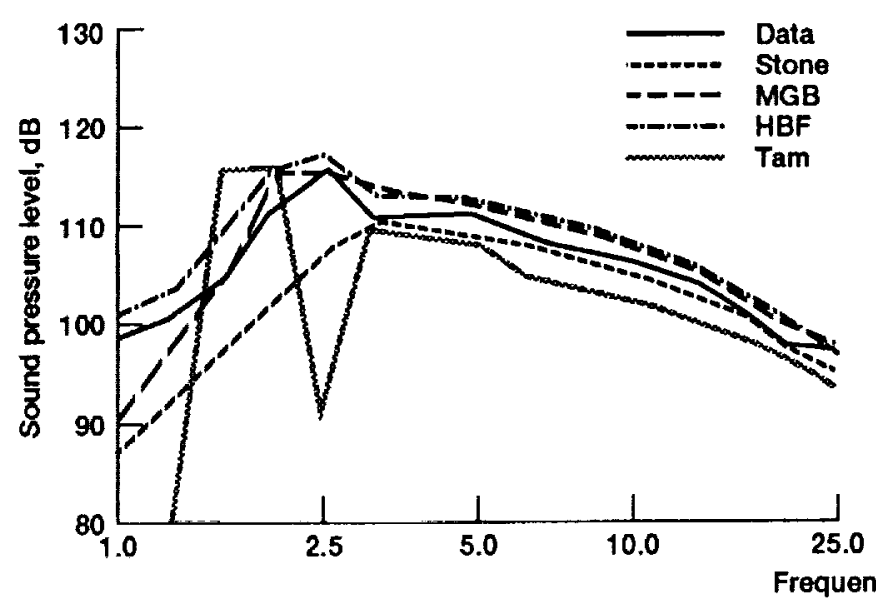

(a) $P R=2.88$.

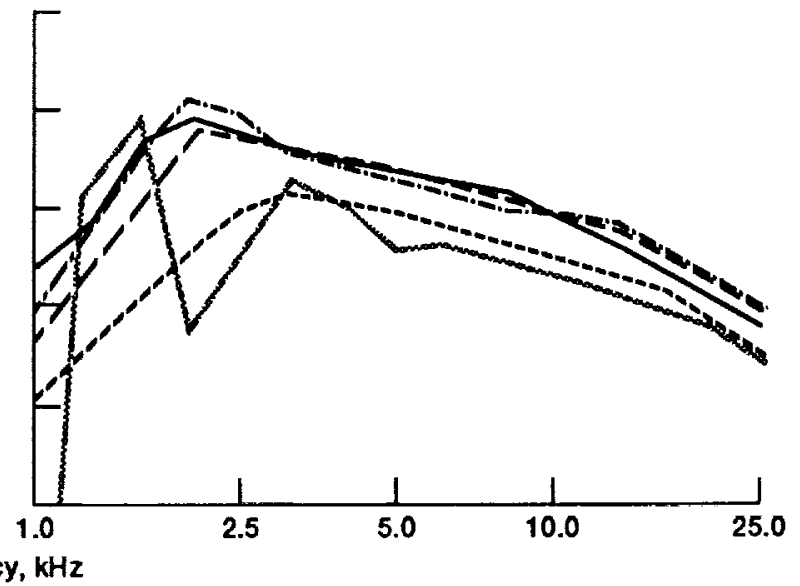

(b) $P R=3.32$.

Flgure 7.-Predicted and measured spectra for a convergent nozzle, flight conditlons. Comparison with flight transformed data $\left(\theta=40^{\circ}\right)$. 


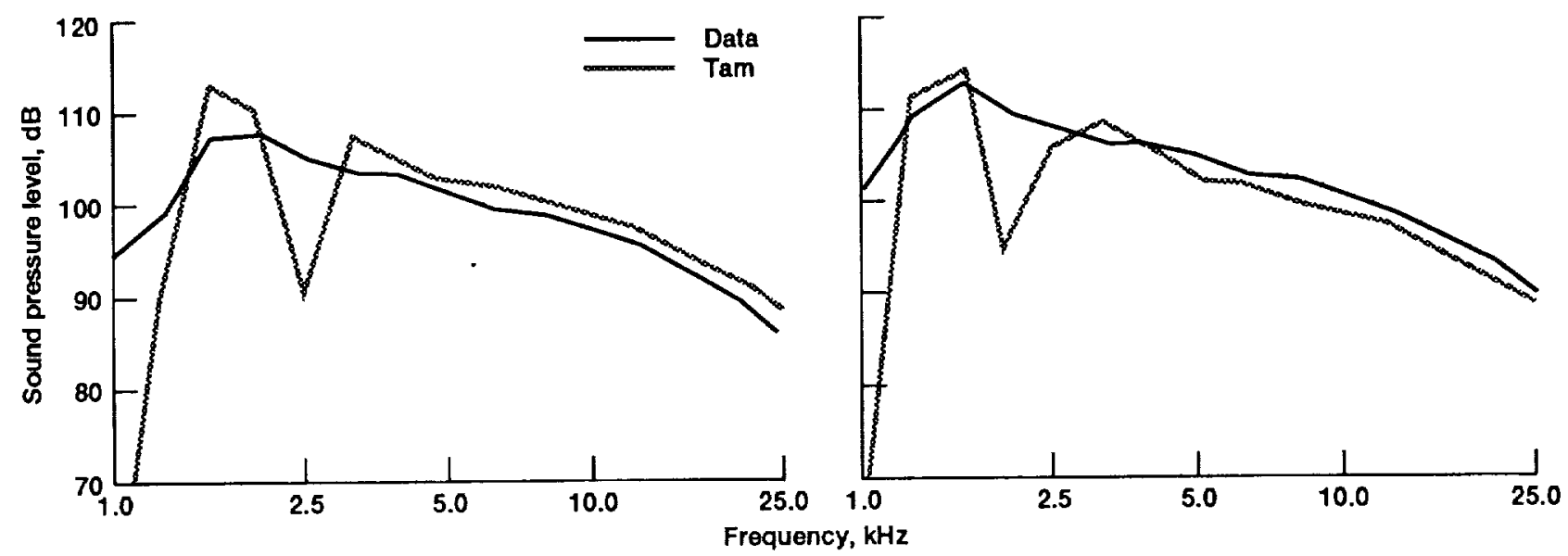

(a) $\mathrm{PR}=2.88$.

(b) $P R=3.32$.

Figure 8.-Predicted and measured spectra for a convergent nozzle, flight conditions. Comparison with free jet data $\left(\theta=40^{\circ}\right)$.

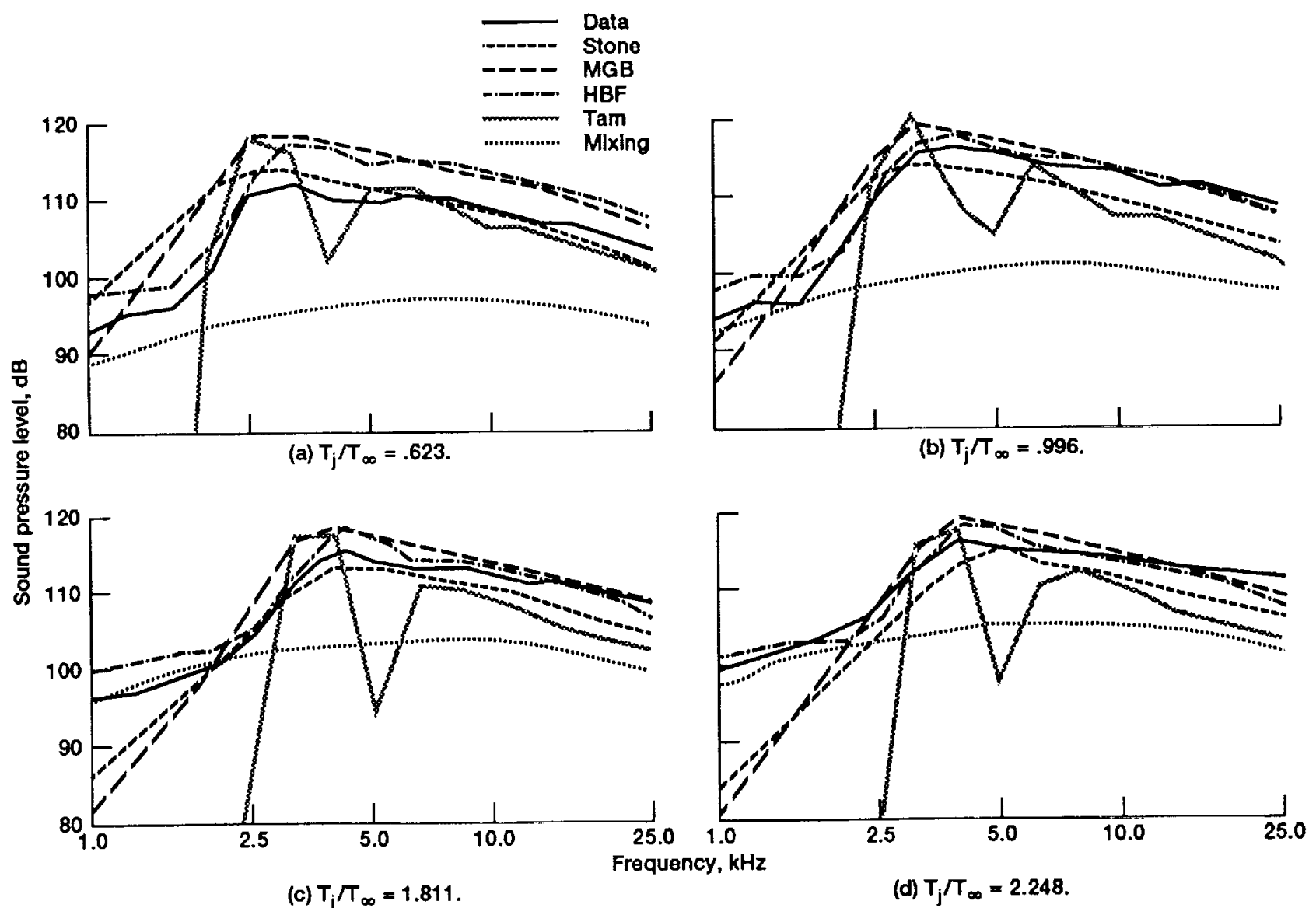

Figure 9. - Predlcted and measured spectra for a convergent nozzle, static conditions at different jet temperatures (PR = $4.73, \theta=45^{\circ}$ ). 


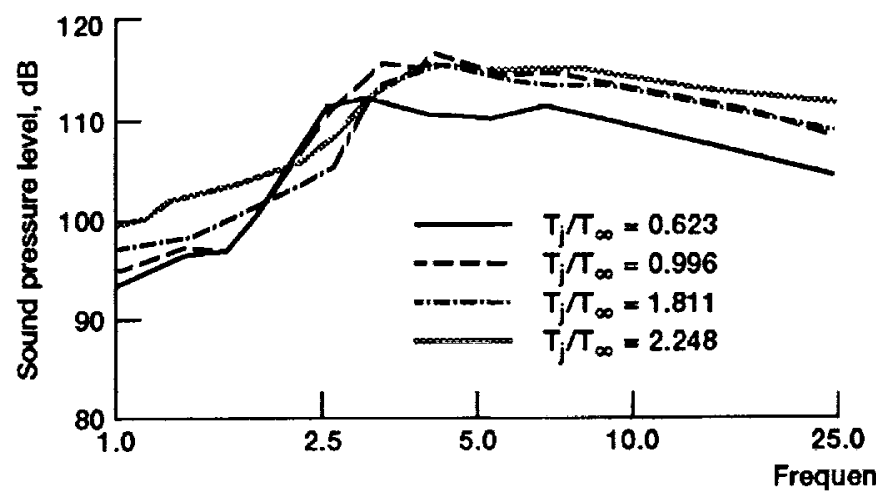

(a) Data.

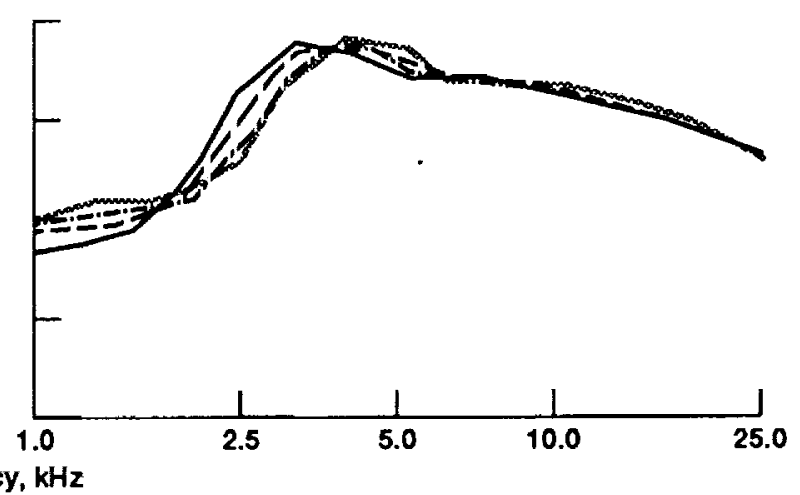

(b) HBF.

Figure 10.-Effects of jet temperatures on the data and predictions $\left(P R=4.73, \theta=45^{\circ}\right)$. 
Public reporting burden for this collection of information Is estimated to average 1 hour per response, including the time for reviewing instructions, searching existing data sources, gathering and maintaining the data needed, and completing and reviewing the collection of information. Send comments regarding this burden estimate or any other aspect of this collection of information, Including suggestions for reducing this burden, to Washington Headquarters Services, Directorate for information Operations and Reports, 1215 Jeflerson Davis Highway, Suite 1204, Arlington, VA 22202-4302, and to the Office of Management and Budget, Paperwork Reduction Project (0704-0188), Washington, DC 20503.
1. AGENCY USE ONLY (Leave blank)
2. REPORT DATE
1992
3. REPORT TYPE AND DATES COVERED
Technical Memorandum

4. TITLE AND SUBTITLE

A Survey of the Broadband Shock Associated Noise Prediction Methods

6. AUTHOR(S)

Chan M. Kim, Eugene A. Krejsa, and Abbas Khavaran
8. PERFoRMING ORgANIZATION REPORT NUMBER

$E-6743$

National Aeronautics and Space Administration

Lewis Research Center

Cleveland, Ohio 44135 - 3191

WU-537-02-23

9. SPONSORING/MONITORING AGENCY NAMES(S) AND ADDRESS(ES)

10. SPONSORING/MONITORING AGENCY REPORT NUMBER

National Aeronautics and Space Administration

Washington, D.C. 20546-0001

NASA TM - 105365

11. SUPPLEMENTARY NOTES

Prepared for the 30th Aerospace Sciences Meeting and Exhibit sponsored by the American Institute of Aeronautics and Astronautics, Reno, Nevada, January 6-9, 1992. Chan M. Kim and Eugene A. Krejsa, NASA Lewis Research Center, Abbas Khavaran, Sverdrup Technology, Inc., Lewis Research Center Group, 2001 Aerospace Parkway, Brook Park, Ohio 44142 (work funded by NASA Contract NAS3-25266). Responsible person, Chan M. Kim, (216) 433-8715.

\begin{tabular}{l|l} 
12a. DISTRIBUTION/AVAILABILITY STATEMENT & 12b. DISTRIBUTION CODE
\end{tabular}

Unclassified - Unlimited

Subject Categories 71 and 07

\section{ABSTRACT (Maximum 200 words)}

Several different prediction methods to estimate the broadband shock associated noise of a supersonic jet are introduced and compared with experimental data at various test conditions. The nozzle geometries considered for comparison include a convergent and a convergent-divergent nozzle, both axisymmetric. Capabilities and limitations of prediction methods in incorporating the two nozzle geometries, flight effect, and temperature effect are discussed. Predicted noise field shows the best agreement for a convergent nozzle geometry under static conditions. Predicted results for nozzles in flight show larger discrepancies from data and more dependable flight data are required for further comparison. Qualitative effects of jet temperature, as observed in experiment, are reproduced in predicted results.

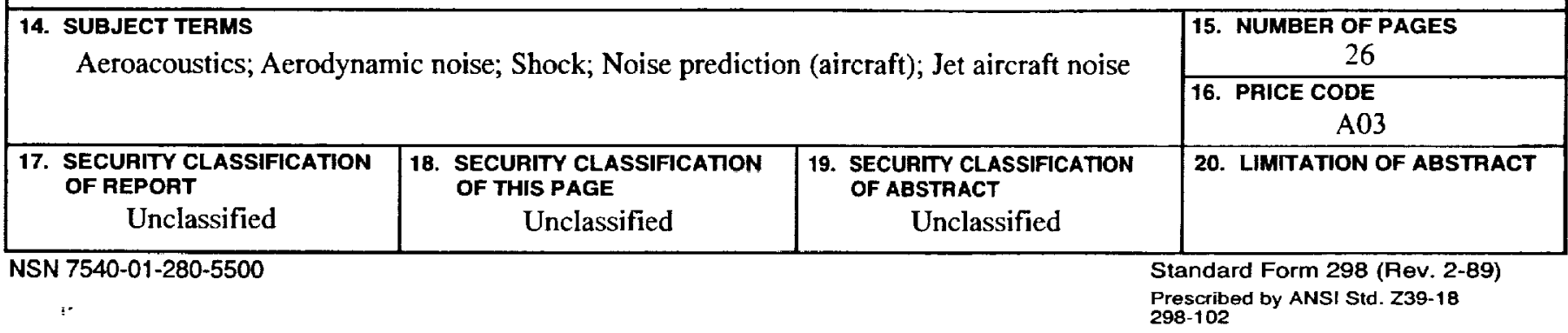


